\title{
Why reduction is underrated
}

DOI:

10.30965/9783957437310_009

\section{Document Version}

Accepted author manuscript

Link to publication record in Manchester Research Explorer

\section{Citation for published version (APA):}

Daly, C. (2019). Why reduction is underrated. In Analysis and Explication in 20th Century Philosophy (1 ed., Vol. 22, pp. 121-136). (Logical Analysis and History of Philosophy). Brill . https://doi.org/10.30965/9783957437310_009

\section{Published in:}

Analysis and Explication in 20th Century Philosophy

\section{Citing this paper}

Please note that where the full-text provided on Manchester Research Explorer is the Author Accepted Manuscript or Proof version this may differ from the final Published version. If citing, it is advised that you check and use the publisher's definitive version.

\section{General rights}

Copyright and moral rights for the publications made accessible in the Research Explorer are retained by the authors and/or other copyright owners and it is a condition of accessing publications that users recognise and abide by the legal requirements associated with these rights.

\section{Takedown policy}

If you believe that this document breaches copyright please refer to the University of Manchester's Takedown Procedures [http://man.ac.uk/04Y6Bo] or contact uml.scholarlycommunications@manchester.ac.uk providing relevant details, so we can investigate your claim.

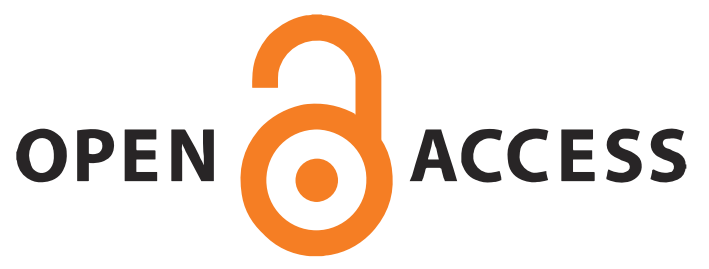




\title{
Why Reduction is Underrated
}

\author{
Christopher Daly, University of Manchester
}

\begin{abstract}
The key idea behind reduction is a simple and familiar one: it's that there's more to things than meets the eye. Surprisingly, this simple idea provides the resources to block a number of notable anti-reductionist arguments: Mackie's argument from queerness against objective moral values, Kripke's Humphrey objection and its recent variants, and Jubien's objection from irrelevance against Lewisian modal realism. What is wrong with each of these arguments is that they suppose that what is to be reduced must not be dissimilar to what it is to be reduced to. This supposition is shown to be misguided and that the success or otherwise of a reduction turns on quite different considerations.
\end{abstract}

\section{Reduction: the key idea}

The key idea behind reduction is a simple and familiar one: it's that there's more to things than meets the eye. We may already know something about some phenomena - colours, numbers, mental states, as the case may be. If we can reduce a phenomenon, we get to know something more. We get to know something more about what it is.

There is a companion idea. Reduction shows that, in another sense, there's less to things than meets the eye. Whatever is reducible is not fundamental. List all the fundamental things and you list everything that exists. You do not need explicitly to list the reduced things. By listing the fundamental things, you implicitly list all the reduced things.

As I am using the notion, reduction is a generic notion. One species of it is conceptual analysis. Here we reduce one set of concepts to another. For example, we know something about the concept of belief but there is more to know. According to logical behaviourism, what more there is to know about the concept of belief is that it can be analysed into - that it is reducible to - concepts of certain kinds of behaviour and dispositions to behave. A second species of reduction is offered by Carnap and Quine's device of explication. Here we reduce a notion of one kind by replacing it with a notion of another, where the latter notion is more precise, clear and testable. For example, perhaps the notion of belief as an all-or-nothing state is to give way to the notion of belief as a state that admits of degree, and perhaps the notion of desire is to give way to the (comparative) notion of preference. A third species of reduction is scientific reduction. Here we reduce one phenomenon to another by reducing the laws governing the one phenomenon to the laws governing the other. For example, we know something about gases from what we observe but there is more to know. According to the kinetic theory of gases, what more there is to know about gases is that they are composed of - that they are reducible to - complexes of molecules. A final 
species of reduction is metaphysical grounding. ${ }^{1}$ Here again we reduce one phenomenon to another. A complex exists in virtue of - the complex is reducible to - the simples that compose it.

Let $\mathrm{F}$ and $\mathrm{G}$ each be domains. Let F-claims be propositions over the F-domain and G-claims propositions over the G-domain. A reduction maps the F-domain ('the target domain') into the G-domain ('the base domain'), and F-claims into G-claims, in systematic ways. In the case of conceptual analysis, the mapping is constrained by conceptual equivalence between F- and G-claims. In the case of scientific reduction, the mapping is constrained by whether the laws governing Fs (or laws very similar to them) can be derived from the laws governing Gs. In the case of grounding, the mapping is constrained by the metaphysical dependence of the Gs on the Fs.

What makes conceptual analysis, explication, scientific reduction, and grounding species of the same genera, and what makes this genera of theoretical interest, is that each of these species entails a shared supervenience thesis. ${ }^{2}$

If Fs are analyzable as Gs, or if talk of Fs is explicated by talk of Gs, or if Fs are scientifically reduced to Gs, or if Gs ground Fs, there is no difference in a world with respect to which things are $G$ without a difference with respect to which things are F. I do not take a stand here on the viability of any of these species of reduction, nor do I take a stand on how they are related to each other. Perhaps a scientific reduction requires a conceptual analysis at some stage (as claimed by Jackson 1998, 57-60). Perhaps a conceptual analysis shows how one concept is grounded by other concepts. I leave these matters open.

Each of the species illustrates what I will call the key idea about reduction. A reduction of Fs is informative because it tells us more about Fs. In particular, it tells us what Fs are. One measure of the informativeness of a reduction of Fs in terms of some other things, Gs, is that Fs are apparently unlike Gs. For the less apparently similar Fs are to Gs, the more we learn when we learn that Fs reduce to Gs. A sample of gas has such properties as temperature, pressure, volume, viscosity and thermal conductivity. The molecules that the gas sample is reduced to individually lack these properties, and they in turn have properties that gas samples lack. If this were not the case, the reduction would fail. The reduction explains why the gas sample has the macroscopic properties it does in terms of things that are not gas samples that lack these macroscopic properties but have certain microscopic properties. To take another example, a reduction of covalent bonding between molecules to electromagnetic forces acting on electrons explains why molecules have the covalent bonds that they in terms of certain other relations between electrons. It is precisely in a reduction that one phenomenon is explained in terms of something apparently dissimilar to it. And now we are in a position to see why the less apparently similar the target and the base domains are to each other, the more informative, and so better, the reduction. The less apparently similar the base domain is, the better the prospect of explaining why the target domain has the distinctive properties that it does.

\footnotetext{
${ }^{1}$ Some philosophers take reduction to be a species of grounding though others deny this. For examples of the former, see Rosen 2010, 124-125 and Schaffer 2009, 378. I mention their view in the interests of completeness, if not accuracy.

${ }^{2}$ Some grounding theorists deny that grounding entails supervenience: e.g. Leuenberger 2014. The matter remains controversial.
} 
The use of the qualifier 'apparently' is deliberate. The reductionist works with a contrast between apparent dissimilarity and genuine similiarity. At the outset of inquiry, Fs are apparently unlike Gs. Part of the value of a reduction of Fs to Gs is that it shows that things that are apparently dissimilar are in fact similar. (Having made this point explicitly, and to avoid prolixity, I will mostly drop the use of the qualifier in what follows. Context will indicate when we are concerned with apparent dissimilarity and when with genuine similarity).

One measure, then, of the informativeness of a reduction of Fs in terms of Gs is how Fs are apparently unlike Gs. Another measure is whether the reduction can be supplemented with a theory of Gs and how good that theory is. For we learn more about what Fs are by knowing that Fs are Gs only in so far as what we know what Gs are.

The above measures should not be taken to be exhaustive. ${ }^{3}$ Other measures that bear on selecting reductions are the theoretical virtues frequently appealed to in theory choice: internal consistency, consistency with background theories, parsimony of ontology, simplicity of formulation, theoretical fertility, and so forth. Just as we may choose between rival theories that agree in their predictions on the basis of the theoretical virtues, we may choose between potential rival reductions of Fs on the same basis. The reason that I single out the above measure of informativeness is just because of its direct role in countering a series of anti-reductionist arguments.

What is so good about achieving a reduction? It furthers understanding: reducing Fs tells us what Fs are. It also solves a potential problem. Suppose that Gs are the only fundamental entities. Then either Fs do not exist or Fs are less fundamental to Gs but reduce to Gs. Reduction shows how Fs are integrated into reality. But isn't there a further option: give up the claim that Gs are the only fundamental entities? Repeated appeal to this option would yield a list of the types of thing that (fundamentally) exist in the form of a long conjunction, rather than the snappy, short list of the types of thing that (fundamentally) exist that the reductionist aspires to (Jackson 1998, 4). Short lists are good, long lists are bad. Why so? Reductions reveal structure. Yet so too do conjunctions, although a conjunction is only one form of structure and a simple one at that. In a conjunction there is just one question: what are the conjuncts? In a reduction there are several: what is involved in the reduction? What is reduced? What is in the reductive base? Two proposed reductions might involve the same entities but differ in what they take to be reduced and what they take to be in the reductive base. The different proposed reductions yield two different structures. If ontology is an answer to the question 'What is there?', structure is an answer to the question 'How is it arranged?', and appealing to reduction is one particular form that structure can take. Information about what is in the reductive base provides two kinds of further information: information about what else there is and how what else there is stands in relation to the reductive base. Suppose that Fs reduced to Gs. Information that there are Fs, and so information that Fs are in the reductive base, provides the further information that there are Fs and that there are Fs because there are Gs. So a benefit that reduction brings is information about structure, information about how different bits of reality are related. If Fs reduced to Gs, then information that there are Gs provides information that there are Fs.

One consequence of this point about structure is that it provides a measure of epistemic reassurance. Suppose that initially we think that there are Fs but doubt creeps in about

\footnotetext{
${ }^{3}$ My thanks to an anonymous referee for this journal for raising this issue.
} 
whether there are such things. Perhaps the things that we have taken to be Fs do not behave as we expect them to. Perhaps we cannot see how there are Fs given that the only fundamental things are Gs. But if Fs reduce to Gs, these doubts may be allayed. There is reason to believe that there are Fs given that there is reason to believe that there are Gs and that Fs reduce to Gs. There is reason to believe that there are dense objects, for example, given that there is reason to believe that there are objects that have mass and volume and that density reduces to mass and volume.

We now have on the table the key idea about reduction. The idea is, I hope, familiar and straightforward enough. Of course, whether there are any successful reductions in science or, more to the point, in philosophy, is a matter for debate. But I think that the debate in philosophy has been significantly hampered by the fact various philosophers have lost sight of the key idea and its significance. Once we remind ourselves of the key idea, certain well-known objections to reductions in various philosophically important fields lapse. In this paper I will consider two cases: objective value and modality.

The plan is as follows. In section 2 I consider whether Mackie's rejection of objective values involves a case against the reduction of such values. In sections 3-4 we turn to modality. In section 3 I assess some recent variants of Kripke's Humphrey objection to David Lewis's reduction of modal claims to claims about objects in other possible worlds. In section $4 \mathrm{I}$ assess the charge that claims about objects in other possible worlds is irrelevant to our understanding of modal claims. In section 5 I offer some thoughts about the proper assessment of reductionist projects.

\section{Mackie on objective values revisited}

Recall the major premise of J.L. Mackie's argument from metaphysical queerness against the existence of objective values:

If there were objective values, then they would be entities or qualities or relations of a very strange sort, utterly different from anything else in the universe. (Mackie 1977, 38)

[Postulating objective values] involves the postulating of value-entities or value-features of quite a different order from anything else with which we are acquainted, and of a corresponding faculty with which to detect them. (Mackie 1977, 40)

What does this consideration show? Divide what putatively exists into objective values and the rest. Vagueness aside, the two groups will be utterly different. By the same reckoning, if we take any non-gerrymandered group of things - say, liquids - we can divide what putatively exists into liquids and the rest. Vagueness aside, the two groups will be utterly different. Now, Mackie does not only say that objective values differ from everything else; he also specifies how they differ from everything else. According to him, objective values are unique in being objectively prescriptive. An objective value is something that necessarily provides a reason for action. It has an objective to-be-doneness that is independent of anyone's desires or interests. ${ }^{4}$ This then is the locus of Mackie's complaint:

\footnotetext{
4 "Objective wrongness, if there is such a thing, is intrinsically prescriptive or action- guiding, it in itself gives or constitutes a reason for not doing the wrong action, and this holds also for some, if not all, other moral features. 
"[the] metaphysical peculiarity of the supposed objective values [is] in that they would have to be intrinsically action-guiding and motivating" (Mackie 1977, 49). How significant is this? If objective prescriptivity is a defining feature of objective value, then of course this is a feature that objective value and nothing else has. If $\varnothing$ is a defining feature of Fs, then, necessarily, all and only Fs have $\varnothing$. Likewise, we can specify what distinguishes liquids from everything else: perhaps, as it might be, all and only liquids flow but have fixed volume.

Recall what is required in a reduction. A reduction requires apparent dissimilarity between the target domain and the base domain, and the more marked the dissimilarity, the more valuable the reduction. Consequently, the more similar Fs are to Gs, the less informative, the less explanatory and the less valuable would be any reduction of Fs to Gs. The limit case of this would be where Fs are utterly similar to Gs. There we have nothing deserving the name of a reduction because there would be nothing informative and explanatory gained by reducing Fs to Gs. There would be nothing more to Fs than meets the eye if Fs were Gs.

So why is Mackie's premise mistaken? He denies that there are objective values and, as part of his case for this, he denies that objective values can be reduced. His reason for denying this is that, he claims, objective values would be "utterly different from anything else in the universe". ${ }^{5}$ But so far from this being a reason to deny that there can be a reduction of objective value, it is a precondition for there being such a reduction.

In a recent discussion of Mackie's argument, Lee Shepski suggests that "the intensifiers in the above passages [i.e. the ones we have quoted] suggest that what is bothering Mackie is the degree to which objective values differ from everything else" (Shepski 2008, 377). But if everything in the universe were an F, or very similar to an F, there could be no reduction of Fs to anything else - no reduction that was sufficiently informative as to tell us much that we did not already know about Fs. It is because there are things that seem utterly different to objective values, that there is a prospect of reducing objective values to something else. Of course, the less similar Fs are to Gs, then, at least at the outset of inquiry, the harder it would be to see how Fs could reduce to Gs. But that is a mark of how unobvious the reduction of Fs to Gs would be and so, in turn, how informative such a reduction would be.

Perhaps, however, we haven't gotten to the heart of Mackie's puzzlement. His puzzlement can be captured by the question: why are they objective values and why are distributed as they are? ${ }^{6}$ Consider the array of facts that are not objective values. Call them the "natural facts'. Given the complete inventory of natural facts, why are they objective values and why do they form the patterns that they do across the natural facts? Mackie writes:

Another way of bringing out this queerness is to ask, about anything that is supposed to have some objective moral quality, how this is linked with its natural features. What is the connection between the natural fact that an action is a piece of deliberate cruelty - say, causing pain just for fun - and the moral fact that it is wrong? It cannot be an entailment, a logical or semantic necessity. Yet it is

To say that they are intrinsically action-guiding is to say that the reasons that they give for doing or for not doing something are independent of that agent's desires or purposes." (Mackie 1981, 114)

5 "Mackie seems to think that all extant things share certain unifying characteristics and that objective moral values cannot be construed as possessing those characteristics." (Shepski 2008, 377)

6 That is, assuming that objective values exist. For ease of exposition, I drop qualifications such as 'if they exist'. 
not merely that the two features occur together. The wrongness must somehow be 'consequential' or 'supervenient'; it is wrong because it is a piece of deliberate cruelty. But just what in the world is signified by this 'because'? (Mackie 1977, 41)

Mackie's puzzlement is perfectly intelligible; it is even a puzzlement that the reductionist (initially) shares. It is puzzling why there are objective values and it is puzzling why they are distributed as they are across the array of natural features. But this is not an obstacle to reduction. It is a motivation for seeking a reduction. One of the benefits of achieving a reduction is that we get to understand why there are objective values and why there are distributed as they are. By the same reckoning, it is puzzling why there is such a thing as heat and why amounts of heat are distributed across the world as they are. This puzzlement, however, is not an obstacle to a reduction of heat; it is something that a reduction of heat is designed to explain. So it is a puzzle that motivates the search for a reduction and a reduction's resolving the puzzle provides a reason to accept the reduction. Facts that are apparently brute - that heat is found in the universe, that amounts of it are distributed in certain patterns, that heat varies according to degree of molecular motion - is shown to be a consequence of certain apparently unrelated facts.

Still, this analogy will not settle matters. Given what he says about objective value, Mackie should have the same sense of puzzlement in the case of heat. He should say something like the following: There are patterns of heat distribution and there are patterns of molecular motion. Yet it is not merely that the two features occur together. The heat must somehow be 'consequential' or 'supervenient'; something is hot because it is a certain pattern of molecular motion. But just what in the world is signified by this 'because'?

That is a good question but I suggest that it shifts the topic at issue. The question isn't specifically about objective value or heat. It is a question about the nature of reduction. Explicating this in terms of conceptual equivalence, nomological equivalence or metaphysical dependence raises issues of their own - issues with the nature of concepts, laws of nature or grounding. But I took it that there was supposed to be a problem specifically facing objective value and its reduction. I took it - wrongly perhaps - that the parties to the debate understood well enough what reduction is at least for the purposes of the debate. I took the issue to be whether objective values can be reduced. I argued that there is a basic deficiency in Mackie's understanding of reduction - that he did not fully appreciate the significance of what I have called the key idea - but presumably what was not at issue was whether the notion of reduction is intelligible or sufficiently clear for use in intellectual inquiry. So while there is much to say and much to debate about what reduction is, I took it that there was enough agreement around the table to address the particular criticisms that have been levelled against the reduction of objective values.

Suppose otherwise. Suppose, as the passage from Mackie might suggest, that the notion of reduction is too problematic and obscure for inclusion in our ideology (where our ideology is concerned with "what ideas can be legitimately had, or what primitive ideas are given to us as a basis for thinking" (Quine 1951, 15)). Yet if that is what is behind the argument from queerness, it would prove too much. For then no reductions would be on the cards. The case against objective value would equally be a case against heat, solidity, density and much else. There would be no non-eliminative solution to what has been called the 'location problem' for these and other features of the world: the problem of saying where these features are in a purely natural world (Jackson 1998, 1-5). I take it 
that Mackie would not want to draw that conclusion. ${ }^{7}$ But it is unclear how his argument could be suitably restricted in scope.

I have interpreted talk of metaphysical queerness in terms of metaphysically queer entities being sui generis - as being unlike everything else. Two other interpretations of that talk are available (Shepski 2008, 375. Shepski exposes the shortcomings of each of these interpretations as a basis for Mackie's argument). One is that metaphysically queer things are ontologically unparsimonious; ${ }^{8}$ the other is that they are mysterious. Given what has already been said, we can be brief with our treatment of these alternative interpretations. First, a universe of Fs and Gs (and nothing else) is less parsimonious than a universe of Fs (and nothing else) only if Fs do not reduce to Gs (or vice versa). So if objective values are reducible to natural features, there is no case for claiming that positing both objective values and natural features is less ontologically parsimonious than positing natural features alone. Second, a domain of entities is mysterious if we do not understand them. But one way of increasing our understanding of Fs is to reduce Fs to Gs. We may understand Gs better than Fs and so, if we discover that Fs reduce to Gs, we increase our understanding of Fs. Or, even if we do not understand Gs better than Fs, we can still improve our understanding of Fs by getting to know how they are related to other things, such as Gs, and that Fs have the features that they do because Gs have the features that they do. To say that objective values are mysterious in the sense of being inexplicable would entail that they cannot be reduced. But, so understood, the premise would beg the question against reductionism about objective value.

For these reasons, these various readings of Mackie's talk of metaphysical queerness provide no force for his argument against objective values if his opponent is a reductionist about objective value.

\section{The Humphrey objection revisited}

David Lewis's modal realism is an elaborate (attempted) reduction of the modal to the nonmodal. One element of the reductive apparatus is counterpart theory. Consider the modal claim that, although a is not F, a might have been F. Counterpart theory renders this as: there is a world in which something $\mathrm{c}$ exists where (1) $\mathrm{c}$ is distinct from $\mathrm{a},(2) \mathrm{c}$ is suitably similar to a, and (3) c is F. There is more to say about counterpart theory and the roles of context and accessibility between worlds in assessing the truth-value of modal claims, but this is enough for our purposes.

Recall Kripke's objection to counterpart theory. We are invited to consider the following modal claim: Humphrey might have won the 1968 presidential election. According to counterpart theory, for that to be true is for there to be a world other than the actual world

\footnotetext{
7 Mackie 1976, 36 endorses error theory about colour - to wit, there are no colours - but does endorse realism about the so-called primary qualities (with solidity relegated to the status of a power). See also Mackie 1977, 39.

8 "One aspect of Mackie's queerness objection rested on his assumption that moral properties would have to be sui generis - belonging in a special ontological category all their own: the non-natural. This claim raised a number of worries, perhaps the most significant of which was the apparent conflict with the widespread commitment to 'ontological parsimony,' the thesis (closely related to Ockham's Razor) that we would do well to avoid committing ourselves to the existence of additional ontological categories if we can reasonably do without them." (Loeb 2003, 44)
} 
in which a person, distinct from the actual Humphrey but very similar to him, wins the presidential election. But, the objection goes, counterpart theory changes the subject. The modal claim was about Humphrey, that man, not some other man, some object distinct from the actual Humphrey. So the modal claim does not reduce to the counterpart claim. Here is what Kripke says:

Strictly speaking, Lewis's view is not a view of 'transworld identification.' Rather, he thinks that similarities across possible worlds determine a counterpart relation which need be neither symmetric nor transitive. The counterpart of something in another possible world is never identical with the thing itself. Thus if we say 'Humphrey might have won the election (if only he had done such-and-such),' we are not talking about something that might have happened to Humphrey but to someone else, a 'counterpart'. Probably, however, Humphrey could not care less whether someone else, no matter how much resembling him, would have been victorious in another possible world. (Kripke 1980, 45, n. 13. See also Plantinga 1974, 114-117)

This familiar objection invites a by-now expected counter. A measure of the informativeness of a reduction of Fs in terms of Gs is that Fs are apparently unlike Gs. Humphrey and his counterpart at another world are apparently unalike; they are, after all, distinct things. But the reduction is precisely that the possibility of Humphrey winning the election reduces to a counterpart of him winning the election. "What Lewis does is to offer an analysis of this fact [the fact that Humphrey might have won the election]: on his account it is a relational fact about Humphrey, consisting of his bearing certain relations to possible worlds and election winners in them." (Hazen 1979, 322) That is why the sentence 'A counterpart of Humphrey won the election' is about Humphrey and says that he might have won the election.

This response might seem to miss something important in Kripke's argument. Kripke presents the argument from Humphrey's perspective. Seen from that first-person perspective, Kripke's charge is that the reduction of 'I might have been president' to 'Someone completely different who largely resembles me might have been president' fails to capture what was said. His charge is that 'we are not talking about something that might have happened to' the referent of the first-person pronoun, but about something happening to some third person, a distinct individual. But (Kripke thinks) we care about our firstpersonal interest and experiences in a different way from third-personal ones, especially ones causally distinct from us which we cannot influence.

I think that presenting Kripke's argument from Humphrey's point of view rather than from a third person point of view does not strengthen it. To illustrate: Humphrey's friend might say of Humphrey: 'He might have been president.' The corresponding Kripkean charge would be that the reduction of that as 'someone completely different who largely resembles him might have been president' fails to capture what was said. The charge would be that charge is that 'we are not talking about something that might have happened to' the referent of the third-person pronoun, but about something happening to a distinct individual. So understood, I do not see any significant difference in force between the firstand the third-person presentations of these arguments.

I now want to consider two recent attempts to restate the Humphrey objection that have not received attention in the literature. First, Gideon Rosen seeks to refurbish the objection. A reduction of modality should, he says, have "fidelity to our prior beliefs: fidelity to our beliefs about what might have been, to our views on the sources of modal knowledge, to 
our general conception of what there is, and so on". But it should have fidelity to something else as well:

What Kripke has done is to point to a rather different but equally important phenomenon: our palpable concern for the modal facts and to urge fidelity here as well. An adequate account will preserve the intelligibility of our caring about the modal truth as we do; of our responding emotionally, morally, and practically to our modal thoughts. The objection is that counterpart theory fails this constraint. We simply do not care about the fortunes of perfect strangers in the immediate way in which we care about our own modal properties. Hence it is implausible to identify the two sorts of fact. (Rosen 1990, 350)

The puzzle about Rosen's refurbished objection is that it seems open to the charge that he acknowledges faces the original objection (or, as he would see it, our initial misreading of the Humphrey objection). Each version of the objection apparently commits the intensional fallacy (as illustrated by such notorious reasoning as: I'm afraid of the masked man but I'm not afraid of the Dean, so the Dean isn't the masked man). Take Rosen's version of the objection. Our caring is discriminatory: we care about our own modal properties in emotional, moral, and practical respects; we care less, if at all, in these ways about the lives of perfect strangers - and that's what the lives of people more or less similar to us at other Lewisian worlds would be. What preserves the intelligibility (as Rosen calls it) of this discrimination is that we don't believe - or perhaps we even disbelieve - that our having modal properties reduces to the goings on of a multitude of perfect strangers. The intelligibility resides in our ignorance. There is nothing untoward in this. Keats revelled in the colours of the rainbow. He was left cold by the physics of light. The difference in his attitudes was intelligible because he did not accept the Newtonian theory of light and its reduction of the colours of the rainbow to lights of different wavelengths. Likewise, in lieu of the requisite reductive principles and our acceptance of them, it is unsurprising that the victory of someone similar to Humphrey might seem to have no bearing on Humphrey's possibly winning. In describing Humphrey's counterpart as a 'perfect stranger', Rosen is using loaded terminology. Lewis's theory is that our counterparts are intelligibly connected to our ordinary concerns because their properties are relevantly akin to our own.

Second, Peter Forrest complains that the premise of Lewis's reduction - that a counterpart of Humphrey won - does not analytically entail the conclusion - that Humphrey might have won:

There is a gap between what the counterparts of Humphrey get up to and the deeds of the man himself. It is rather like Hume's gap between 'is' and 'ought'. Contrast that with the following inference, where the premiss does analytically entail the conclusion: 'Some twelve-toed counterpart of Humphrey did win, so someone with twelve toes could have won'. I submit that if $p$ is said to have as a sufficient truth-condition $q$, then $q$ should analytically entail $p$. Hence counterpart theory fails. (Forrest 2004, 173)

The reductionist has the options of rejecting or accepting Forrest's proposal. The first option might take as its model a construal of scientific reduction, whereby the reduction of (say) gases to systems of molecules is not mediated by an analytic entailment (Block \& Stalnaker 1999). But the second option is more concessive to Forrest and so is dialectically more effective. Analytic entailments may be more or less obvious. What Forrest's argument shows is that the inference is not an obvious analytic entailment. That leaves open whether it is an unobvious analytic entailment. On one view there is a distinction between 
semantically shallow terms, such as 'chair', which furnish only trivial analytic entailments, and semantically deep terms, such as 'knowledge,' 'justification,' 'free will', and 'person', which furnish substantive and unobvious analytic entailments. ${ }^{9}$ It is this class of terms, and the sentences in which they feature, that the reductionist would seek to exploit. Moreover, if a given reduction supplies analytic entailments between the target sentences and the base sentences, then unless those analytic entailments are unobvious ones, the reduction would fail. The putative reduction would fail to tell us more than we knew at the outset about the phenomena to be reduced.

Every unobvious analytic entailment can be made more obvious by supplementing the premise with analytic definitions of the terms involved in the premise and conclusion. The reductionist can duly take counterpart theory to furnish, for any sentence of the form 'possibly, a is F', an analytically equivalent sentence of the form 'some counterpart of a is F'. Whatever final assessment should be made of this option, perhaps it does not depart from what Lewis himself thought. In Counterfactuals he claimed that sentences of the form 'possibly, p' are 'paraphrasable' as sentences of the form 'at some world, p' (Lewis 1973, 85-86), and he endorsed this paraphrase strategy even after having published On The Plurality of Worlds. ${ }^{10}$ Now, if Lewis took paraphrases as expressing analytic equivalences, then he could endorse the reductionist's reply to Forrest. I hesitate to say this was Lewis' chosen view. ${ }^{11}$ My own view is that the contents of the sentences involved in the putative paraphrase leaves at least underdetermined whether the paraphrase expresses an analytic equivalence (Nolan 2002, 31)

\section{The irrelevance objection to modal realism}

So far we have concentrated on counterpart theory, but there is a more general concern of the same sort that some philosophers have about Lewis's modal realism. ${ }^{12}$ This is the charge that the collection of Lewisian worlds is irrelevant to the nature of modality:

Since other worlds are conceived by Lewis to be things of the same sort as the actual world, their existence should be reckoned to be every bit as 'independent' as that of the actual world. In particular, their existence (and nature) should not be seen as dependent upon our concepts, intuitions, how we use language, or, in general, on anything that happens in our world. This makes it very hard to see how what goes on in other such 'worlds' can have anything to do with what is really possible. (Jubien 1989, 303)

\footnotetext{
${ }^{9}$ Fricker 1991, $\$ 5$ contrasts concepts such as that of chair with what she calls 'semantically deep concepts', such as the concepts of knowledge, justification, free will and person. She takes this contrast between concepts to be the basis for a linguistic distinction, namely one between relatively trivial analyticities, on the one hand, and substantive and unobvious analyticities, on the other.

${ }^{10}$ Chihara records a personal communication from Lewis dated $2^{\text {nd }}$ April 1996 in which Lewis expressed his continued endorsement of his 1973 view: Chihara 1998, 86, n. 22.

11 I leave open the question whether Lewis would endorse the reductionist strategy. Did he think that paraphrases expressed analytic equivalences? Against: as a student of Quine's, Lewis would know how controversial such a view was. For: as a former student of Oxford philosophy, Lewis retained a place for conceptual analysis in his philosophy. See especially Lewis 1994.

12 Van Inwagen writes that those who believe there are possible worlds "face the problem of explaining what these things would have to do with modality if there were any of them" (van Inwagen 1985, 119, n. 15).
} 
As long as other worlds are entirely distinct, independent things (at least physically), it is hard to see how they can have anything at all to do with the truth or falsity of simple statements of possibility. (Jubien 1989, 304)

Jubien argues from the independence of Lewisian worlds to their irrelevance to modality, but how does the independence of worlds license the inference? Jubien mentions two kinds of independence. In the first quotation, he remarks that Lewisian worlds are independent of "our concepts, intuitions, how we use language, or, in general, on anything that happens in our world". But how would this militate against the reduction of modality to Lewisian worlds? Suppose, for instance, that Lewisian worlds - or some other collection of phenomena - were dependent on our concepts, intuitions, language, or whatever happens in our world. It is unclear how that would aid the reduction of modality, for it is unclear that there is any special connection between (a) our concepts, intuitions, language, or whatever happens in our world and (b) the nature of modality. In the second quotation, Jubien remarks that "other worlds are entirely distinct, independent things (at least physically)" from our world. But again how would this militate against the reduction of modality to Lewisian worlds? Suppose Lewisian worlds were dependent, partly or wholly, on our world. It is unclear how that would advance the prospects of a reduction of modality to Lewisian worlds. But if it is not clear, it is hard to see how the (spatio-temporal) independence of Lewisian worlds from our world undermines the prospects of a reduction of modality to Lewisian worlds. Moreover, what kind or kinds of independence are at issue? Jubien mentions the physical independence of Lewisian worlds from our world; nothing that happens at our world causally affects what happens at any Lewisian world (nor conversely). Yet supposing that Lewisian worlds were physically dependent on our world (i.e. there was overlap between worlds) would not seem to enhance the prospects of a reduction of modality to Lewisian worlds. And insofar as we might imagine other respects in which Lewisian worlds are dependent on our world (such as grounding), similar considerations apply.

Jubien offers a theological thought experiment to strengthen his case (Jubien 1989, 304). Suppose God creates everything that exists. God has two options in order to do this. One option is to create our world and all the Lewisian worlds. The other option is to create only our world. Now consider the modal truth that Jubien could have been a cab driver. That would be true on the first option. There would be a world fairly similar to the actual at which a person fairly similar to Jubien is a cab driver. But, Jubien claims, it would also be true on the second option that he could have been a cab driver. Since there are no Lewisian worlds on the second option, this shows the irrelevance of Lewisian worlds to modal truth and hence modality.

I do not think that this thought experiment adds anything to the debate. It is a picturesque way of advancing the following stark claim: if there were no Lewisian worlds, the truthvalues of modal claims would remain as they are. ${ }^{13}$ That flatly contradicts Lewis's theory but is not an argument against it. Jubien takes God to have the following option: of not creating Lewisian worlds despite all the modal truths holding. God has this option, however, only if it is metaphysically possible for all the modal truths to hold although there are

\footnotetext{
13 Jubien has to be assuming that there are no modal truths about Lewisian worlds themselves. For the sake of argument let's follow him in this.
} 
no Lewisian worlds. But whether this is metaphysically possible is precisely the question whether Lewis's modal realism is correct. Jubien has not advanced the debate but has only begged the question against Lewis. ${ }^{14}$

Jubien's charge of irrelevance against Lewis's modal realism also seems at odds with the dialectic. If Lewis had simply stated his theory - his proposed reduction of modality to worlds - and left matters there, then the charge of irrelevance might seem more understandable and one deserving to be addressed. The puzzle, however, is that Lewis had done more than this. He had presented a notable case for modal realism: namely, that if modality is reduced to Lewisian worlds, it has a hefty payoff. There are no modal primitives and a wealth of phenomena - properties, propositions, causation, supervenience, counterfactuals and more - can be accounted for in terms of sets of worlds (Lewis 1986, ch. 1). The puzzle facing Jubien's presentation of the charge of irrelevance is that Lewis's case for his modal realism - Lewis's case for saying that Lewisian worlds are relevant to modality - is overlooked. ${ }^{15}$

\section{Conclusion}

Finally I want to look at some more general issues concerning reduction. The common element to the objections that we've considered was that there is 'no good candidate' to reduce the target domain to or, at any rate, none of the candidates proposed - natural facts or counterparts, respectively - are good enough. A quite different line of criticism would be that there are 'too many' reductions. Here the criticism is that the target domain fails to be reduced to the base domain not because the target domain has some feature the base domain lacks. Instead, the criticism is that the target domain can apparently be reduced to distinct base domains, but, precisely because these base domains are distinct, it is concluded that the target domain does not reduce to any of these base domains.

This line of criticism is present in the following two arguments found in the literature. The arguments are reductios. On the assumption that Fs can be reduced to Gs, they can also be reduced to Hs, where Hs are distinct from Gs. Since Fs cannot be reduced both to Gs and to Hs, it is concluded that Fs cannot be reduced to either.

Here is a reconstruction of the argument of Benacerraf (1965):

\section{What are natural numbers?}

(1) Natural numbers can be reduced to von Neumann sets.

(2) Natural numbers can be reduced to Zermelo sets.

(3) Von Neumann sets and Zermelo sets are distinct.

(4) So natural numbers cannot be reduced to these sets; mutatis mutandis, they are shown to be sui generis.

${ }^{14}$ For an extensive discussion of the pitfalls facing appeals to what we can imagine God doing as a guide to possibility, see Hanrahan 2009.

15 Or, perhaps, largely overlooked. Jubien thinks that Lewis responds to the irrelevance objection by running it together with a response to another objection - an objection by van Inwagen to Lewis's indexical treatment of actuality (Jubien 1989, 304-305). I think it is uncharitable to take Lewis's response to the irrelevance objection to be exclusively bound up with his response to this other objection, especially given the interpretation available in the text. See also Maguire 2013, 145-146. 
Here is a reconstruction of the argument of Moore (1999):

\section{What are propositions?}

(1) Propositions can be reduced to Fregean Thoughts.

(2) Propositions can be reduced to Russellian $n$-tuples of particulars and attributes.

(3) Fregean Thoughts and Russellian $n$-tuples are distinct.

(4) So propositions cannot be reduced to these entities; mutatis mutandis, they are shown to be sui generis.

The topic of too many reductions deserves a more extensive treatment than I can give it here, but I will offer some comments. A first issue to be clarified is whether arguments from 'too many reductions' are epistemic or metaphysical in intent. If such an argument is epistemic, it would claim that, because there are many equally good candidates for reducing Fs, we have no reason to believe that the Fs reduce to any of those candidates. Note, first, that it is not obvious how this argument, so understood, does more than exploit the familiar fact that theory is underdetermined by evidence. But then the argument would provide no stronger case against reduction than the case that is already faced by currently accepted scientific theory. Second, if the 'too many reductions' argument does exploit the underdetermination of reduction by data, then one should expect its proponents to draw the epistemic conclusion that we have no reason to accept one of the candidate reductions rather than any of the others. That would be agnosticism. But that conclusion does not warrant the following ambitious metaphysical conclusion: that the target domain exists but does not reduce to any of the base domains. If the data available (in practice or even in principle) fails to tell us what Fs reduce to, it does not follow that the data tells us that Fs are not reducible (see also Bealer 1982, 125). If the data in a country house murder is consistent with the butler having done it but also consistent with the gardener having done it, it does not follow that neither of them did it and that the murderer is some third party.

Much of the plausibility of arguments of the 'too many reductions' variety lies in the fact that they are content to take a reduction to be a mapping from the target domain to the base domain and to leave matters there. No further means of assessment of proposed reductions is considered. But it should not be surprising that more than one reduction meets the constraint that the F-domain maps into the G-domain. This leaves it open whether additional information about the reductions - particularly whether each of them can be embedded in a broader series of reductions that give a systematic account of a broader domain of phenomena (see Oddie 2001, § 9). To take the reduction of natural numbers, there is a good case for reducing them to the finite von Neumann sets (e.g., given consideration concerning recursiveness, well-ordering principles, continuity at transfinite limits, and minimality) rather than the Zermelo sets. ${ }^{16}$

In some cases of reduction it may be that some mild form of elimination is in keeping. How so? Perhaps we, the folk, have it wrong. We think there are (say) objective values but there are no objective values as we think of them. We think there are events occurring absolutely simultaneously but there are no absolutely simultaneous events. Similar claims might be advanced, perhaps, for colour and free will. What to say about such claims? The point to emphasise is that cases where we get it wrong can often still be 'salvageable':

\footnotetext{
${ }^{16}$ Details are provided by Steinhart 2003. See also Doane-Clarke 2008.
} 
we get some important things wrong about objective values or simultaneity, as the case may be, but not everything. It might be that there are no objective values as we think of them, but there are objective values*, where these are what we are disposed to value (Lewis 2000, 93). It might be that there are no simultaneous events as we think of them, but there are simultaneous* events, where events are simultaneous* relative to a common reference frame. The target domains for reduction are then the domains of objective value* and simultaneous* events. I suspect that it is widely thought that Carnapian explication is opposed to conceptual analysis: doesn't explication stipulate new meanings for new words whereas conceptual analysis uncovers the meanings of familiar words? True enough, but that is no opposition. Suppose some mild form of eliminativism about Fs is in order but, in fact, there exist Fs*, entities importantly similar to Fs. Talk of Fs can be explicated by - that is to say, replaced by - talk of Fs*. But now talk of Fs* is a suitable subject for conceptual analysis. Perhaps, for example, talk of heat and cold is (at least in scientific practice) to be replaced by talk of temperature (Carnap 1950, chapter 1 and Strang 1960). This raises the question of how talk of temperature is itself to be understood, and that is a task that conceptual analysis may undertake. Putting the issue in terms of the more general framework of reduction, there are cases where there are some phenomena that we, the folk, have misconceived and we have preserved this misconception by describing the phenomena as Fs. The reduction tells us that the phenomena are not Fs but Fs*. The reduction thereby tells us not simply something about the phenomena that we did not know before, but that something we thought about the phenomena was itself mistaken.

There may be other considerations that close off the prospect of reduction. (See, for example, Moore 1903, chapter 1) for an objection to putative ethical reductions that are knowable a priori and Barnett 2002 for an objection to putative ethical reductions that are knowable only a posteriori). What would block a reduction is some feature of the target domain not explained by the base domain. ${ }^{17}$ Dissimilarity does not precluding correlating principles between the Fs and the Gs. To see this, suppose that the Fs are fairly similar to the Gs. That would not make the reduction of Fs to Gs any easier. So the similarity - or dissimilarity - of Fs to Gs has no bearing on the prospects of a reduction of the Fs to the Gs.

This makes the task for reductionism in one way easier - there is no constraint of similarity between the target domain and the base domain - but in another way harder - for the objects in one domain to explain features of the objects of another requires more than a mapping between the domains. Who would have thought otherwise? Yet presentations of objections to various reductionist projects often veer between these two ways. All parties know that the task for reductionism about the mental is to explain how mental states reduce to physical ones. Yet there is a prevalent tendency to suggest that the reduction is blocked because of the apparent dissimilarity between the mental - 'technicolour phenomenology' -

17 Perhaps Mackie thought he had isolated such a feature. According to him, objective value is something we are necessarily disposed to value. But if the sole candidate for the base domain consists in our dispositions to value, and it is contingent what we value, then, strictly speaking, there is no objective value (Lewis 2000, 90). The problem here, however, is with this specification of objective value. It is controversial whether objective value would be objectively prescriptive in the motivating sense (Shepski 2008, 372). 
and the physical - 'soggy grey matter'. ${ }^{18}$ Such picturesque comments are an irrelevance and only distract from the key idea of reduction.

\section{Bibliography}

Barnett, D. 2002. Against “A Posteriori” Moral Naturalism. Philosophical Studies 107, 239-257.

Bealer, G. 1982. Quality and Concept. Oxford: Oxford University Press.

Benacerraf, P. 1965. What Numbers Could Not Be. The Philosophical Review 74, 47-73.

Block, N. \& Stalnaker, R. 1999. Conceptual Analysis, Dualism and the Explanatory Gap. The Philosophical Review 108, 1-46.

Carnap, R. 1950. Logical Foundations of Probability. Chicago: University of Chicago Press.

Chihara, C. S. 1998. The Worlds of Possibility: Modal Realism and the Semantics of Modal Logic. Oxford: Clarendon Press.

Doane-Clarke, J. 2008. Multiple Reductions Revisited. Philosophia Mathematica 16, 244-255.

Forrest, P. 2004. Review of J. Divers' Possible Worlds. Mind 113, 171-174.

Fricker, E. 1991. Analyticity, Linguistic Practice, and Philosophical Method. In: Puhl, K. (ed.). Meaning Scepticism. Berlin: De Gruyter.

Hanrahan, B. 2009. Getting God Out of Our (Modal) Business. Sophia 48, 379-391.

Hazen, A. 1979. Counterpart Theoretic Semantics for Modal Languages. Journal of Philosophy 76, 319-338.

Jackson, F. 1998. From Metaphysics to Ethics: A Defence of Conceptual Analysis. Oxford: Oxford University Press.

Jubien, M. 1989. Problems with Possible Worlds. In: Austin, D.F. (ed.). Philosophical Analysis. Dordrecht: Kluwer Academic Publishers.

Kripke, S. 1980. Naming and Necessity. Oxford: Blackwell.

Leuenberger, S. 2014. From Grounding to Supervenience? Erkenntnis 79, 227-240.

Lewis, D. 1973. Counterfactuals. Oxford: Blackwell.

Lewis, D. 1986. On the Plurality of Worlds. Oxford: Blackwell.

Lewis, D. 1994. Reduction of Mind. In: Guttenplan, S. (ed.). Companion to the Philosophy of Mind. Oxford: Blackwell.

Lewis, D. 2000. Dispositional Theories of Value. In: Lewis, D. Papers in Ethics and Social Philosophy. Cambridge: Cambridge University Press.

Loeb, D. 2003. Gastronomic Realism - A Cautionary Tale. Journal of Theoretical and Philosophical Psychology 23, 30-49.

McGinn, C. 1989. Can We Solve The Mind-Body Problem? Mind 98, 349-366.

Mackie, J.L. 1976. Problems from Locke. Oxford: Oxford University Press.

Mackie, J.L. 1977. Ethics: Inventing Right and Wrong. Harmondsworth: Penguin Books.

Mackie, J.L. 1981. The Miracle of Theism: Arguments For and Against The Existence of God. Oxford: Oxford University Press.

Maguire, B. 2013. Defending David Lewis's Modal Reduction. Philosophical Studies 166, 129-147.

Moore, G.E. 1903. Principia Ethica. Cambridge: Cambridge University Press.

Moore, J. 1999. Propositions, Numbers and the Problem of Arbitrary Identification. Synthese 120, 229-263.

Nolan, D. P. 2002. Topics in the Philosophy of Possible Worlds. London: Routledge.

Oddie, G. 2001. Scrumptious Functions. Grazer Philosophische Studien 62, 137-156.

Plantinga, A. 1974. The Nature of Necessity. Oxford: Oxford University Press.

18 The phrases are McGinn's: see McGinn 1989, 349. 
Quine, W.V. 1951. Ideology and Ontology. Philosophical Studies 2, 11-15.

Rosen, G. 1990. Modal Fictionalism. Mind 99, 327-354.

Rosen, G. 2010. Metaphysical Dependence: Grounding and Reduction. In: Hale, B. \& Hoffmann, A. (eds.). Modality Metaphysics, Logic, and Epistemology. Oxford: Oxford University Press.

Schaffer, J. 2009. On What Grounds What. In: Chalmers, D. et al. (eds.). Metametaphysics: New Essays on the Foundations of Ontology. Oxford: Oxford University Press.

Shepski, L. 2008. The Vanishing Argument from Queerness. Australasian Journal of Philosophy 86, 371-387.

Steinhart, E. 2003. Why Numbers Are Sets. Synthese 133, 343-361.

Strang, C. 1960. The Perception of Heat. Proceedings of the Aristotelian Society 61, 239-252.

Van Inwagen, P. 1985. Plantinga on Trans-world Identity. In: van Inwagen, P. (ed.), Alvin Plantinga: A Profile. Dordrecht: D. Reidel. 